Note

\title{
Selection of Trichogramma species as potential natural enemies for the control of Opogona sacchari (Bojer)
}

\author{
Mayara de Carli ${ }^{1}$, Aloisio Coelho Júnior ${ }^{2 *}$, José Maria Milanez ${ }^{3}$, Cristiane Nardi ${ }^{1}$, José Roberto Postali Parra ${ }^{2}$
}

${ }^{1}$ State University of Central-West of Paraná - Lab. of Agricultural Entomology, R. Simeão Camargo Varela de Sá, 3 - 85040-080 - Guarapuava, PR - Brazil.

2University of São Paulo/ESALQ - Dept. of Entomology and Acarology - Lab. of Insect Biology, Av. Pádua Dias, 11 13418-900 - Piracicaba, SP - Brazil.

${ }^{3}$ Agricultural Research and Rural Extension of Santa

Catarina/tajaí Experimental Station, Rod. Antônio Heil, 6800

- 88318-112 - Itajaí, SC - Brazil.

*Corresponding author <aloisiocoelho@usp.br>

Edited by: Richard V. Glatz

Received June 14, 2016

Accepted September 23, 2016
ABSTRACT: The banana moth Opogona sacchari (Bojer) (Lepidoptera: Tineidae) is a polyphagous pest that can cause serious damage, especially to banana crops in southern Brazil. It attacks the fruit, lowering its quality and making bananas unsuitable for export. Current control measures are limited and the use of Trichogramma (Hymenoptera: Trichogrammatidae) for Applied Biological Control may be an alternative for the management of this pest. In this study, we investigated the potential parasitism effectiveness of eggs of 0 . sacchari by $T$. pretiosum, $T$. atopovirilia and T. galloi, three species of parasitoids commonly used in Applied Biological Control programs in Brazil. Eggs of 0 . sacchari were parasitized by all three Trichogramma species, and $T$. atopovirilia and T. galloi were the most aggressive, showing greater potential for control of this pest in the banana culture.

Keywords: IPM, banana moth, biological control

\section{Introduction}

The banana moth Opogona sacchari (Bojer) (Lepidoptera: Tineidae) is a major pest in banana plants in different regions of Brazil. It attacks all parts of the plant except for the roots and leaves (Davis and Peña, 1990). The larva penetrates the fruit and forms galleries, reducing its commercial value (Jang et al., 2010). $O$. sacchari is polyphagous and has been reported to attack coffee, pineapple, papaya, bamboo, corn, sugarcane, stored tubers, and ornamental plants (Peña et al., 1990). The presence of this insect has hindered export of bananas, since it is an A1 or A2 quarantine pest in other countries (Cheraghian, 2013; Eppo, 2015; Senasa, 2016; USDA, 2016), including Argentina (Senasa, 2016), the major importer of Brazilian bananas (FAO, 2014).

To the best of our knowledge, biological control methods have not been used to manage this pest, although the use of microorganisms and parasitoids seem promising. Egg parasitoids of the genus Trichogramma have been intensively studied and used in applied biological control programs (Gomes and Parra, 2008; Parra, 2014) because of their efficiency, wide geographic distribution, easiness of laboratory rearing, and large numbers of hosts, more than 200 hosts belonging to 70 families and more than eight insect orders (Hassan, 1993). Lack of information on biological control agents for $O$. sacchari and demand for control methods that can reduce the use of agrochemicals highlight the importance of research on natural enemies that are able to control this pest. In this study, we investigated the effectiveness and parasitism potential of three species of Trichogramma, T. pretiosum Riley, T. atopovirilia Oatman \& Platner, and T. galloi Zucchi, on eggs of $O$. sacchari, and evaluated the possibility of using them in the biological control of this pest.

\section{Materials and Methods}

Specimens of $O$. sacchari were collected from banana plantations in Santa Catarina (Ilhota, Luis Alves, Schröeder, Corupá, Massaranduba, and Jaraguá do Sul municipalities) and reared under laboratory conditions, using the diet developed by Greene et al. (1976), with modifications. Eggs obtained from this laboratory colony were used in the bioassays. Adults of T. galloi, T. pretiosum, and T. atopovirilia were obtained from the laboratory stock. The adults were reared on eggs of the factitious host Anagasta kuehniella (Zeller).

Females of each species of Trichogramma to be tested $(\mathrm{N}=25)$, which were newly emerged and had already copulated, were placed in individual glass vials $(\varnothing 1 \times h 7 \mathrm{~cm})$. One honey droplet was placed in the walls of the vials as a food source for adult females. The vials were sealed with PVC film and kept in climate-controlled chambers at $25 \pm 1{ }^{\circ} \mathrm{C}, 75 \pm 10$ $\%$ relative humidity $(\mathrm{RH})$, and a photophase of $14 \mathrm{~h}$. Daily, about 40 eggs of $O$. sacchari were attached to a cardboard $(\varnothing 0.5 \times h 4 \mathrm{~cm})$ and offered to the females of Trichogramma, isolated in the vial. This procedure was repeated daily until the females died to assess longevity. 
The egg masses, less than $24 \mathrm{~h}$ old, were collected daily from the vials containing the females and placed in a new vial $(\varnothing 1 \times h 7 \mathrm{~cm})$. These "new" vials with the supposed parasitized egg masses were kept at $25 \pm$ $1{ }^{\circ} \mathrm{C}, 75 \pm 10 \% \mathrm{RH}$, and a photophase of $14 \mathrm{~h}$ until emergence was complete. Afterward, the dark eggs were counted to assess the total parasitism, as well as the eggs with an exit hole to assess the emergence rate. The sex ratio was determined using the proportion of males to females emerged through the equation:

$$
\text { sex ratio }=\frac{n \text {. of females }}{n \text {. of females }+n \text {. of males }}
$$

and males and females were distinguished by their antennae (Pinto, 1999). Parasitism viability (emergence rate) of the three Trichogramma species was evaluated using the proportion of the number of eggs with an exit hole for the number of darkened eggs. Longevity of females was evaluated through the daily observation of mortality. The number of insects that emerged was also counted.

For each Trichogramma species, 25 females (repetitions) were evaluated, and a completely randomized design was used. The Quasi-Poisson generalized linear models (Demétrio et al., 2014) were fitted to the data for parasitism rate, number of insects emerged, and number of insects per egg. A quasi-binomial generalized linear model was fitted to the data for viability and sex ratio. When the deviance analysis indicated significant treatment effects $(p<0.05)$, multiple comparisons were performed using the $95 \%$ confidence intervals for the linear predictors. The goodness-of-fit for all models was assessed using half-normal plots with a simulated envelope (Demétrio et al., 2014). Kaplan-Meier estimates for the adult lifespan were obtained for each treatment, and the pairwise tests were performed using the log-rank tests $(p=$ 0.05) (Matthews and Farewell, 2007). All analyses were performed using the statistical software " $\mathrm{R}$ " version 3.2.2.

\section{Results and Discussion}

All three Trichogramma species parasitized the eggs of $O$. sacchari; however, the parasitoids differed in the number of eggs parasitized $(\mathrm{F}=3.71, \mathrm{df}=2, P=$ $0.03)$, viability $(\mathrm{F}=7.4307, \mathrm{df}=2, P=0.0012)$, number of emerged parasitoids $(\mathrm{F}=6.62, \mathrm{df}=2, P=0.002)$, and sex ratio $(\mathrm{F}=3.1903, \mathrm{df}=2, P=0.025)$ (Table 1$)$. In contrast, the longevity data $\left(\chi^{2}=2.1 \mathrm{df}=2, P=0.345\right)$ and number of insects per egg $(\mathrm{F}=2.3047$, df $=2, P=$ 0.1081 ) did not differ between T. galloi, T. pretiosum, and T. atopovirilia.

The total parasitism observed was 36 to 57 eggs, on average; $T$. atopovirilia and $T$. galloi were the most aggressive species. These species parasitized about $20 \%$ more eggs than T. pretiosum (Table 1) did. More individuals of T. atopovirilia emerged than T. pretiosum, while T. galloi was statistically similar to both. The parasitism viability (emergence percentage) ranged from $50 \%$ for T. pretiosum to $60 \%$ for $T$. atopovirilia and T. galloi. The sex ratio differed between the species. T. pretiosum had a higher proportion of males ( $\mathrm{F}=3.1903, \mathrm{df}=2, P=0.025)$. According Russel and Stouthamer (2010), it is highly desirable that a biocontrol agent has a higher proportion of females. Low proportion of females in a population of parasitoids can occur due to variation in ecological variables such as host size or nutritional facts (Luck et al., 2001).

To the best of our knowledge, this is the first report on parasitism of species of Trichogramma on eggs of $O$. sacchari. The eggs were parasitized by all three Trichogramma species. T. atopovirilia and T. galloi showed the highest parasitism capacity as well as larger number of parasitoids emerged.

The parasitism capacity of $T$. atopovirilia, that is, the total number of eggs parasitized (eggs that became dark) by one of Trichogramma species, was higher than that of T. pretiosum for eggs of Spodoptera frugiperda (JE Smith) (Beserra et al., 2005) and of Stenoma catenifer Walsingham (Nava et al., 2007). In general, T. galloi has a higher parasitism capacity than that of T. pretiosum for Diatraea saccharalis (Fabricius) eggs, as these eggs are rarely parasitized by T. pretiosum (Monje, 1995).

Zucchi et al. (1991) found that T. galloi was the most abundant species on $D$. saccharalis eggs, which, similarly to $O$. sacchari eggs, are arranged in clusters and are flattened. This shape could explain why T. galloi parasitizes more intensively eggs of $O$. sacchari.

The parasitism capacity and viability of parasitoids is related to the size and nutritional quality of the host eggs (Bai et al., 1992; Cônsoli and Vinson, 2012), host age (Vinson, 2010; Zhang et al., 2014; Song et al., 2015) and physical barriers to oviposition (Beserra et al., 2005). These factors directly affect population maintenance of natural enemies, a key factor for natural or classical biological control (Flint and Driestadt, 1998). However, the

Table 1 - Number of parasitized eggs, number of emerged parasitoids, parasitism viability parasitoid sex ratio, parasitoids emerged per egg, and longevity of Trichogramma galloi, T. pretiosum and T. atopovirilia on eggs of Opogona sacchari reared at $25 \pm 1^{\circ}, 75 \pm 10 \% \mathrm{RH}$ and a photophase of $14 \mathrm{~h}$.

\begin{tabular}{lcccccc}
\hline Species & $\begin{array}{c}\text { Number of parasitized eggs } s^{\mathrm{a}} \\
( \pm \mathrm{SE}))^{\mathrm{c}}\end{array}$ & $\begin{array}{c}\text { Number of emerged parasitoids }{ }^{\mathrm{a}} \\
( \pm \mathrm{SE})\end{array}$ & $\begin{array}{c}\text { Viability }^{\mathrm{b}} \\
( \pm \mathrm{SE})\end{array}$ & $\begin{array}{c}\text { Sex ratio }^{\mathrm{a}} \\
( \pm \mathrm{SE})\end{array}$ & $\begin{array}{c}\text { Parasitoids emerged per egg }^{\mathrm{b}} \\
( \pm \mathrm{SE})\end{array}$ & $\begin{array}{c}\text { Longevity }^{\mathrm{b}} \\
( \pm \mathrm{SE})\end{array}$ \\
\hline T. galloi & $51.43 \pm 5.17 \mathrm{ab}$ & $19.6 \pm 2.0 \mathrm{ab}$ & $58.0 \pm 5.6 \mathrm{a}$ & $0.73 \pm 0.019 \mathrm{a}$ & $1.1 \pm 0.04$ & $8.0 \pm 0.9$ \\
T. pretiosum & $36.45 \pm 5.17 \mathrm{~b}$ & $14.1 \pm 2.3 \mathrm{~b}$ & $50.9 \pm 6.8 \mathrm{~b}$ & $0.50 \pm 0.06 \mathrm{~b}$ & $1.1 \pm 0.03$ & $9.0 \pm 1.0$ \\
T. atopovirilia & $57.74 \pm 4.57 \mathrm{a}$ & $26.8 \pm 2.3 \mathrm{a}$ & $58.6 \pm 5.9 \mathrm{a}$ & $0.66 \pm 0.04 \mathrm{a}$ & $1.03 \pm 0.01$ & $8.0 \pm 0.6$ \\
\hline
\end{tabular}

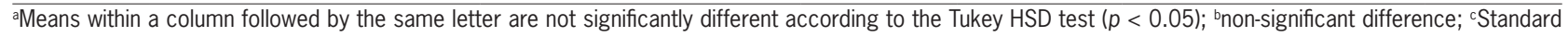
error. 
most important factor in selecting a parasitoid species for applied biological control programs (programs where a large number of natural enemies were released and control level is reached faster) would be the mortality rate generated by the parasitoid after release, even if it does not become established in the area (Flint and Driestadt, 1998).

In this study, T. atopovirilia and T. galloi caused high mortality of eggs of $O$. sacchari. Overall, the data confirmed that $T$. atopovirilia and $T$. galloi were promising biocontrol agents for O. sacchari, better than T. pretiosum, having potential to be used in applied biological control programs targeted at this insect pest species.

\section{Acknowledgments}

We thank Janet W. Reid, JWR Associates, for the English revision. We also thank the National Institute of Semiochemicals in Agriculture (Process no. 573761/20086) for financial support.

\section{References}

Bai, B.; Luck, R.F.; Lisa, F.; Stephens, B.; Janssen, J.A.M. 1992. The effect of host size on quality attributes of the egg parasitoid, Trichogramma pretiosum. Entomologia Experimentalis et Applicata 64: 37-48.

Beserra, E.B.; Dias, C.T.; Parra, J.R.P. 2005. Behavior of Trichogramma atopovirilia Oatman \& Platner and T. pretiosum Riley (Hymenoptera: Trichogrammatidae) on Spodoptera frugiperda (J. E. Smith) (Lepidoptera: Noctuidae) egg masses. Brazilian Journal of Biology 65: 9-17.

Cheraghian, A. 2013. Banana moth: Opogona sacchari Bojer (Lepidoptera: Tineidae): a guide for diagnosis detection of quarantine pests. Available at: http://ppo.ir/LinkClick.aspx ?fileticket $=$ hoeJ7pmQ1bM\%3D\&tabid $=884$ [Accessed Apr $14,2016]$

Cônsoli, F.; Vinson, S. 2012. Parasitoids (Hymenoptera). p. 515538. In: Panizzi, A.R.; Parra, J.R.P., eds. Insect bioecology and nutrition for integrated pest management. Taylor and Francis, New York, NY, USA.

Davis, R.D.; Peña, J. 1990. Biology and morphology of the banana moth, Opogona sacchari (Bojer), and its introduction into Florida (Lepidoptera: Tineidae). Proceedings of the Entomological Society of Washington 92: 593-618.

Demétrio, C.G.B.; Hinde, J.; Moral, R.A. 2014. Models for overdispersed data in entomology. p. 219-259. In: Ferreira, C.P.; Godoy, W.A.C., eds. Ecological modeling applied to entomology. Springer, New York, NY, USA.

European and Mediterranean Plant Protection Organization [EPPO]. 2015. EPPO A1 and A2 lists of pests recommended for regulation as quarantine pest. Available at: http:// archives.eppo.int/EPPOStandards/PM1_GENERAL/pm102(24)_A1A2_2015.pdf [Accessed Apr 14, 2016]

Food and Agriculture Organization of the United Nations [FAO]. 2014. Banana market review and banana statistics 2012-2013. Available at: http://www.fao.org/docrep/019/ i3627e/i3627e.pdf [Accessed June 14, 2016]
Flint, M.L.; Driestadt, S.H. 1998. Natural Enemies Handbook: The Illustrated Guide to Biological Pest Control. ANR Publications, Oakland, CA, USA.

Greene, G.L.; Leppla, N.C.; Dickerson, W.A. 1976. Velvetbean caterpillar: a rearing procedure and artificial medium. Journal of Economic Entomology 69: 487-488.

Hassan, S. 1993. The mass rearing and utilization of Trichogramma to control lepidopterous pests: achievements and outlook. Pesticides Science 37: 387-391.

Jang, E.B.; Siderhurst, M.S.; Hollingsworth, R.G.; Showalter, D.N.; Troyer, E.J. 2010. Sex attractant for the banana moth, Opogona sacchari Bojer (Lepidoptera: Tineidae): provisional identification and field evaluation. Pest Management Science 66: 454-460.

Luck, R.F.; Janssen, J.A.M.; Pinto, J.D.; Oatman, E.R. 2001. Precise sex allocation, local mate competition, and sex ratio shifts in the parasitoid wasp Trichogramma pretiosum. Behavioral Ecology and Sociobiology 49: 311-321.

Matthews, D.E.; Farewell, V.T. 2007. The log-rank or Mantel-Haenszel test for the comparison of survival curves. p. 67-75. In: Matthews, D.E.; Farewell, V.T., eds. Using and understanding medical statistics. Karger, Basel, Switzerland.

Monje, J.C. 1995. Present significance of Trichogramma spp. (Hym., Trichogrammatidae) for the control of sugarcane borers in the Americas. Mitteilungen der Deutschen Gesellschaft fur Allgemeine und Angewandte Entomologie 10: 208-290.

Nava, D.E.; Takahashi, K.M.; Parra, J.R.P. 2007. Trichogramma and Trichogrammatoidea strains to control Stenoma catenifer. Pesquisa Agropecuária Brasileira 42: 9-16 (in Portuguese, with abstract in English).

Parra, J.R.P. 2014. Biological control in Brazil: an overview. Scientia Agricola 715: 420-429.

Parra, J.R.P., Zucchi, R.A., Coelho Jr., A., Geremias, L.D., Cônsoli, F.L., 2015. Trichogramma as a tool for IPM in Brazil. p. 472-496. In: Vinson, B., Greenberg, S.M., Liu, T., Rao, A., Volosciuk, L.F., eds., Augmentative Biological Control using Trichogramma spp.: Current Status and Perspectives. Northwest A\&F University Press, China.

Pinto, J.D. 1999. Systematics of the North American Species of Trichogramma Westwood (Hymenoptera: Trichogrammatidae). Entomological Society of Washington, Washington, DC, USA.

Peña, J.E.; Duncan, R.; Torres, V. 1990. Dynamics and control of the banana moth on foliage plants. Proceedings of the Florida State Horticultural Society 103: 189-192.

Russell, J.E.; Stouthamer, R. 2010. Sex ratio modulators of egg parasitoids. p. 167-190. In: Consoli, F.L.; Parra, J.R.P. Zucchi, R.A., eds. Egg parasitoids in agroecosystems with emphasis on Trichogramma. Springer, Amsterdam, The Netherlands.

Servicio Nacional de Sanidad y Calidad Agroalimentaria [SENASA]. 2016. Lists of quarantine pests for Argentina $=$ Listas de plagas cuarentenarias para Argentina Available at: https://www.ippc.int/static/media/files/ reportingobligation/2016/02/16/Quarantine_Pest_List_of Argentina_-_2016.pdf [Accessed Apr 14, 2016] (in Spanish). 
Song, L.W.; Wen, X.Y.; Zang, L.S.; Ruan, C.C.; Shi, S.S.; Shao, X.W.; Zhang, F. 2015. Parasitism and suitability of different egg ages of the Leguminivora glycinivorella (Lepidoptera: Tortricidae) for three indigenous Trichogramma species. Journal of Economic Entomology 108: 933-939.

United States Department of Agriculture [USDA]. 2016. USDA APHIS regulated pest list. Available at: http://www.invasive. org/species/list.cfm?id = 4 [Accessed Oct 04, 2016]

Vinson, S.B.; 2010. Nutritional ecology of insect egg parasitoids. p. 25-55. In: Consoli, F.L.; Parra, J.R.P.; Zucchi, RA., eds. Egg parasitoids in agroecosystems with emphasis on Trichogramma. Springer, Amsterdam, The Netherlands.
Zhang, J.J.; Ren, B.Z.; Yuan, X.H.; Zang, L.S.; Ruan, C.C.; Sun, G.Z.; Shao, X.W. 2014. Effects of host-egg ages on host selection and suitability of four Chinese Trichogramma species, egg parasitoids of the rice striped stem borer, Chilo suppressalis. BioControl 59: 159-166.

Zucchi, R.A.; Parra, J.R.P.; Silveira Neto, S. 1991. Trichogramma species associated with some lepidopterous in Brazil. Colloquesde-I'INRA 56: 131-134. 